Revista Brasileira de Agricultura Irrigada v.10, no.6, p. 1011 - 1022, 2016

ISSN 1982-7679 (On-line)

Fortaleza, CE, INOVAGRI - http://www.inovagri.org.br

DOI: 10.7127/rbai.v10n600481

Protocolo 481.16 - 06/09/2016 Aprovado em 21/12/2016

\title{
ANALISE COMPARATIVA DA QUALIDADE DE ÁGUA PARA IRRIGAÇÃO EM TRÊS SISTEMAS HÍDRICOS CONECTADOS NO SEMIÁRIDO
}

\author{
Camila Alves de Souza ${ }^{1}$, Yara Rodrigues Araujo ${ }^{2}$, José Ribeiro de Araújo Neto ${ }^{3}$, Helba \\ Araújo de Queiroz Palácio ${ }^{4}$, Bruno Eduardo Alves Barros ${ }^{5}$
}

\begin{abstract}
RESUMO
O conhecimento do teor total de sais solúveis presentes na água e o comportamento de seus íons dominantes permite a utilização e manejo de forma mais adequada no uso para agricultura irrigada. Nesse contexto, o presente trabalho teve como objetivo avaliar a dinâmica dos sais nas águas superficiais e subterrâneas para fins de irrigação em três sistemas hídricos no semiárido brasileiro: o açude Trussu, o Trecho perenizado do rio Trussu e poços localizados ao longo do vale do rio perenizado. A área em estudo encontra-se localizada na bacia do Alto Jaguaribe, no município de Iguatu, Ceará, Brasil. As coletas foram realizadas no período de março de 2013 a março de 2015, no total de 10 coletas em 14 estações amostrais. Os parâmetros monitorados foram: sódio, cálcio, magnésio, bicarbonato, carbonato, Cloreto e sulfato, foram calculadas as razões de adsorção de sódio normal e corrigida, além da condutividade elétrica da água. Em seguida, aplicou-se o diagrama de Piper na definição das classes das águas. As águas foram classificadas como cloretada cálcica, bicarbonatada cálcica, bicarbonatada sódica para as águas superficiais e subterrâneas e cloretadas sódicas para as águas subterrâneas. Quanto à classificação para a irrigação os resultados mostraram que as águas superficiais, apresentaram baixo risco de gerar problemas de salinidade, já as subterrâneas mostraram um risco de médio a alto risco de causar salinidade. Quanto à sodicidade as águas superficiais não apresentam problemas, já as subterrâneas encontraram-se com problemas de sodicidade podendo ser utilizadas apenas em solos com manejo adequado dos sais.
\end{abstract}

Palavras-chaves: Salinidade. Sodicidade. Diagrama de Piper. Sais.

\footnotetext{
1 Discente de graduação em Tecnologia em Irrigação e Drenagem - IFCE, Campus Iguatu. E-mail: camilaifce2014@gmail.com;

2 Discente de graduação em Tecnologia em Irrigação e Drenagem - IFCE, Campus Iguatu. E-mail: yaraaraujo20@hotmail.com;

${ }^{3}$ Doutorando em Engenharia Agrícola na DENA/CCA/UFC, Técnico em laboratório de solos, água e tecidos vegetais, LABAS/IFCE Campus Iguatu. E-mail: juniorifcelabas@gmail.com;

4 Professora do IFCE - Campus Iguatu e Doutora em Engenharia Agrícola DENA/CCA/UFC. E-mail: helbaraujo23@yahoo.com.br;

${ }^{5}$ Graduado em Tecnologia em Irrigação e Drenagem - IFCE Campus Iguatu e Mestrando em Engenharia Agrícola na Universidade Federal Rural de Pernambuco, Email: beduardo@outlook.com.
} 


\title{
COMPARATIVE ANALYSIS OF THE QUALITY OF WATER FOR IRRIGATION IN THREE WATER SYSTEMS CONNECTED IN THE SEMIARID
}

\begin{abstract}
Knowledge of the total content of soluble salts present in the water and the behavior of their dominant ions allows the use and management more adequately in use for irrigated agriculture. In this context, this study aimed to evaluate the dynamics of salts in surface and ground water for irrigation purposes in three water systems in the Brazilian semiarid region: the Trussu weir, the perennial Excerpt from Trussu river and wells located along the river valley perennial. The study area is located in the basin of Alto Jaguaribe in the city of Iguatu, Ceará, Brazil. Samples were collected from March 2013 to March 2015, a total of 10 collections in 14 sampling stations. The parameters monitored were: sodium, calcium, magnesium, bicarbonate, carbonate, chloride and sulfate, the sodium adsorption normal ratios were calculated and corrected, besides the electric conductivity. Then applied the Piper diagram in the definition of the water classes. The waters were classified as chlorinated contains calcium, bicarbonated contains calcium, bicarbonated sodium for surface and ground water and chlorinated sodic into groundwater. Regarding the classification for irrigation results showed that surface water showed low risk of generating salinity problems, since the underground showed a risk of medium to high risk of causing salinity. As for sodicity surface water present no problems, since the underground are with sodicity problems can only be used on soils with adequate management of salts.
\end{abstract}

Keywords: Salinity. Sodicity. Piper diagram. Salts.

\section{INTRODUÇÃO}

O semiárido nordestino é caracterizado por curtos períodos de chuva seguidos de longos períodos de seca, ou seja, uma região que concentra um baixo percentual de água disponível em qualidade e quantidade, com má distribuição e elevadas perdas atmosféricas por evaporação e baixas taxas de precipitação (ANDRADE et al., 2010a; GHEYI et al., 2012), diante desse fato pressupõe o uso da irrigação para atender às necessidades hídricas das plantas (ARRAES et al., 2007). No entanto, essa água de irrigação deve ser de boa qualidade e usada de forma sustentável (FROTA JÚNIOR et al, 2007). Segundo Almeida (2010), as águas utilizadas para irrigação normalmente são de origem superficiais ou subterrâneas.

As águas superficiais do semiárido geralmente são de melhor qualidade, mas apresentam grande variabilidade devido à fácil diluição dos sais, aos períodos de sangria ou extravasamento. As águas dos rios perenizados artificialmente apresentam quase as mesmas características dos açudes (ANTAS; MORAIS, 2011). Lobato et al. (2008) destacam que essas águas são verdadeiros depósitos de elementos químicos que circulam nos ecossistemas e nos sedimentos, cuja fonte é representada pela água de drenagem resultante da precipitação sobre a área da bacia.

Existem, também, as águas subterrâneas encontradas abaixo do subsolo, onde formam os lençóis freáticos. Essas águas são as que mais enfrentam problemas por conta da dificuldade com a diluição dos sais, podendo também ocorrer contaminação do solo por produtos químicos e dejetos de animais. O conhecimento da qualidade da água subterrânea, relativo aos sais, torna-se ferramenta necessária ao planejamento da exploração desse recurso e ao manejo empregado, quando destinada à irrigação (ANDRADE JÚNIOR et al., 2006)

O conhecimento da composição iônica da água é fundamental quando se deseja avaliar a sua qualidade para fins agronômicos e, mais precisamente, quanto ao uso na irrigação (BARROSO et al., 2011). Quando se refere à qualidade físico-química das águas que se destinam à irrigação, devem ser avaliadas principalmente sob três aspectos, considerados importantes na determinação da qualidade 
agronômica das mesmas, sendo eles: salinidade, sodicidade e toxidade dos íons (VASCONCELOS et al., 2009).

A salinidade é a quantidade de sais dissolvidos em um determinado corpo de água. Seus efeitos causam problemas em áreas agrícolas quando os sais se acumulam na zona radicular e alcançam elevadas concentrações, reduzindo a produtividade do solo e ocasionando perdas na produção das culturas (AYERS \& WESTCOT, 1999). A sodicidade se baseia essencialmente no efeito do sódio nas condições físicas do solo, pois em altas quantidades na água ocasionam a dispersão das partículas do solo com isso causando problemas de infiltração (RICHARDS 1954).

A toxidade é um problema interno á planta e que se produz quando determinados íons, são absorvidos principalmente pelas raízes, se acumulam nas folhas mediante a transpiração, chegando a alcançar concentrações nocivas (ALMEIDA, 2010).
Nesse contexto, o presente trabalho teve por objetivo comparar a qualidade das águas para irrigação de três sistemas hídricos conectados: açude, rio perenizado e poços localizados ao longo do rio Trussu perenizado no semiárido tropical brasileiro.

\section{MATERIAL E MÉTODOS}

A bacia do reservatório Trussu está situada na região centro sul do estado do Ceará na Bacia do Alto Jaguaribe, ocupando uma área de $1.590 \mathrm{~km}^{2}$ (Figura 1). A referida bacia drena o rio que leva o mesmo nome rio Trussu, que apresenta $24 \mathrm{~km}$ perenizados àjusante do reservatório. A vazão regularizada para a perenização da parte baixa do vale pode variar de 0,2 até $4,5 \mathrm{~m}^{3} \cdot \mathrm{s}^{-1}$, isso é em decorrência do grande déficit hídrico na região durante o período seco. Durante o percurso de perenização encontram-se os poços, pontos de coleta da água subterrânea.


Figura 1. Localização da bacia do açude Trussu e do trecho perenizado do rio Trussu na bacia do Alto Jaguaribe, Ceará.

As condições climáticas da bacia hidrográfica do reservatório Trussu no município de Iguatu, Ceará, são semiáridas com estação seca no verão, evapotranspiração potencial média anual (2230,5 mm) superior à precipitação média anual $(867,0 \mathrm{~mm})$ e temperaturas mínimas e máximas variando entre $20,3^{\circ} \mathrm{C}$ e $31,7^{\circ} \mathrm{C}$, a radiação solar média anual é de $5,63 \mathrm{kWh} \mathrm{m}^{-2}$ dia ${ }^{-1}$, insolação de 2897,6 h ano ${ }^{-1}$ (INMET, 2014). O clima da região é do tipo BSw'h' (Semiárido quente), de acordo com a 
classificação climática de Köppen (BARROSO et al., 2011).

O açude e trecho perenizado do rio Trussu tem importante papel no abastecimento da região, sendo suas águas destinadas para diversos usos: abastecimento humano, irrigação, industrial, aquicultura, turismo e lazer.

De acordo com a Companhia de Gestão de Recursos Hídricos do Ceará - COGERH são 15 outorgantes cadastrados ao uso das águas do açude Trussu e 104 outorgantes cadastrados no rio Trussu, onde o principal uso outorgado é a agricultura irrigada, representando $87,4 \%$ das outorgas. O principal método de irrigação utilizado é aspersão, representando $82 \%$ das áreas irrigadas, sendo 9\% inundação e 9\% microaspersão. Totalizando uma área irrigada outorgada de 160,3 há. As principais culturas exploradas nestas áreas são pastagem, milho, feijão, cana de açúcar, ainda fruticultura: goiaba, melancia, uva, entre outros.

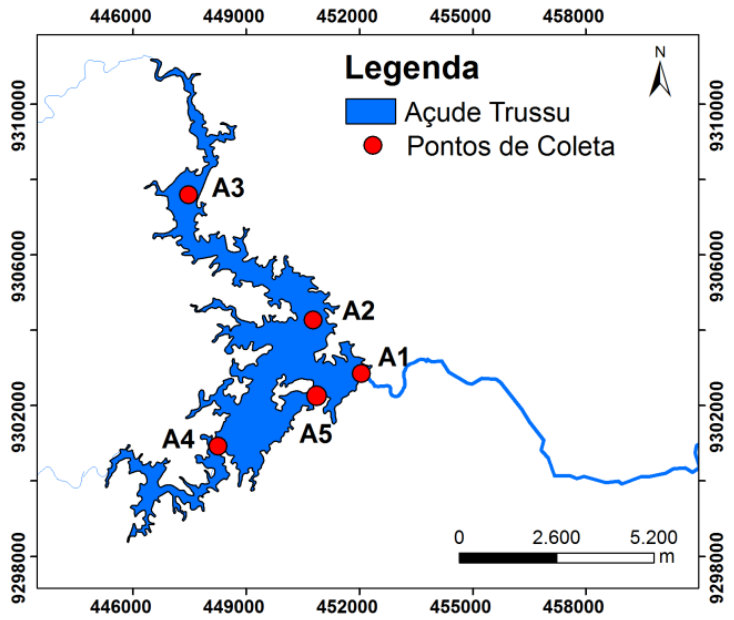

(a)
As coletas foram realizadas bimestralmente, no período de abril de 2013 a março de 2015 em 14 estações amostrais, sendo 5 pontos de coletas das águas superficiais do reservatório Trussu (Figura 2a) e 9 pontos de coletas ao longo do trecho perenizado do rio Trussu, destes 5 eram nas aguas superficiais no trecho do rio perenizado onde, a estação amostral R1 foi situada no ponto inicial da perenização do rio, local onde é lançada a água pela galeria do açude Trussu, R2 foi localizada no Sítio Pedreiras, a R3 próximo à Vila de Santa Clara, a R4 após a Vila Varjota e a R5 no Sitio Barra, local onde o rio Trussu deságua à margem esquerda do rio Jaguaribe; e 4 em poços às margens do trecho do rio perenizado, sendo P1 e P2 localizados na Várzea da Lama próximos ao leito do rio Trussu, a estação P3 na Vila de Barreiras dos Pinheiros e a P4 fica localizada na Vila de Varjota (Figura 2b).

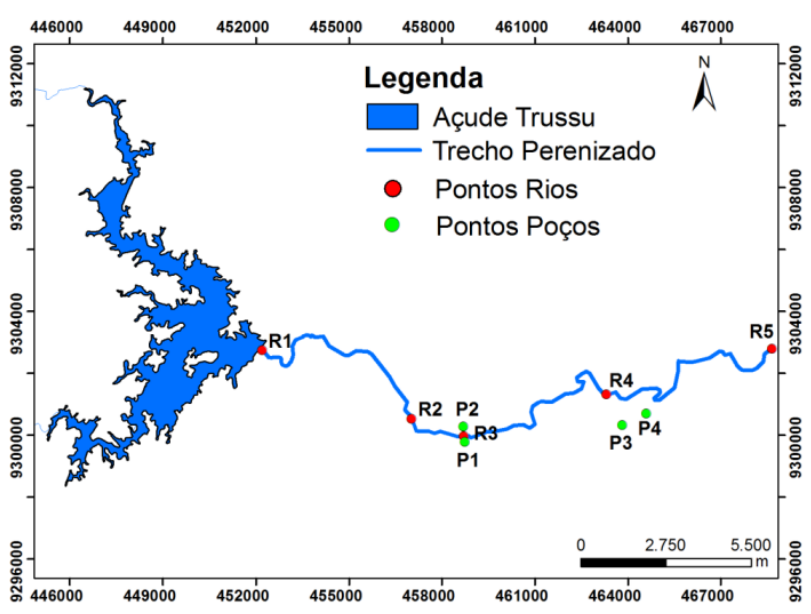

(b)

Figura 2. Sistemas hídricos: (A) Açude Trussu, e (B) Águas superficiais e subterrâneas no Trecho perenizado do rio Trussu, Ceará.

Todas as amostras foram coletadas em frascos plásticos brancos, com capacidade de 2L, acondicionadas em caixas exotérmicas e conduzidas para 0 laboratório para a realização das análises de sódio $\left(\mathrm{Na}^{+}\right)$, cálcio $\left(\mathrm{Ca}^{+2}\right)$, magnésio $\left(\mathrm{Mg}^{+2}\right)$, bicarbonato $\left(\mathrm{HCO}_{3}{ }^{-}\right)$, carbonato $\left(\mathrm{CO}_{3}{ }^{-2}\right)$, Cloreto $\left(\mathrm{Cl}^{-}\right)$e sulfato $\left(\mathrm{SO}_{4}{ }^{-2}\right)$. Também foram calculadas as razões de adsorção de sódio normal e corrigida (RAS e $\mathrm{RAS}^{\circ}$ ), além de medidos os valores condutividade elétrica da água (CE). As análises foram realizadas de acordo com APHA (1995), no Laboratório de Análises de Água e Solo LABAS do Instituto Federal de Educação, Ciência e Tecnologia do Ceará - IFCE, Campus Iguatu.

A partir dos valores de $\mathrm{Na}^{+}\left(\mathrm{mmol}_{\mathrm{c}} \mathrm{L}^{-1}\right)$, $\mathrm{Ca}^{+2}\left(\mathrm{mmol}_{\mathrm{c}} \mathrm{L}^{-1}\right)$ e $\mathrm{Mg}^{+2}\left(\mathrm{mmol}_{\mathrm{c}} \mathrm{L}^{-1}\right)$, foi calculada a RAS através da seguinte expressão: 


$$
\boldsymbol{R A S}=\frac{N a}{\sqrt{\frac{C a+M g}{2}}}
$$

Foi adotada a classificação de água proposta pelo Laboratório de Salinidade do United States Department of Agricultural (USDA), que utiliza a CE como indicadora da salinidade e a RAS como indicadora de sodicidade (RICHARDS, 1954).

Também foi avaliada a RAS $^{\circ}$, que analisa os problemas de infiltração, causados nos solos por concentrações altas de sódio ou baixas de cálcio nas águas utilizadas para irrigação. Ela considera o cálcio corrigido pela salinidade da água (CE) para o teor de bicarbonato. A razão de adsorção de sódio corrigida $\left(\mathrm{RAS}^{\circ}\right)$ é calculada mediante a seguinte expressão:

$$
\boldsymbol{R A S ^ { \circ }}=\frac{N a}{\sqrt{\frac{C a^{\circ}+M g}{2}}}
$$

Onde:

Na: teor de sódio na água, $\operatorname{mmol}_{\mathrm{c}} \mathrm{L}^{-1}$;

$\mathbf{C a}^{\circ}$ : teor de cálcio da água, corrigido pela salinidade da água (CE) para o teor de bicarbonato em relação ao seu próprio teor de cálcio $\left(\mathrm{HCO}_{3} / \mathrm{Ca}\right), \mathrm{mmol}_{\mathrm{c} .} \mathrm{L}^{-1}$

Mg: teor de magnésio na água, $\mathrm{mmol}_{\mathrm{C}} \mathrm{L}^{-1}$.

Na Tabela 1 verifica-se os padrões de qualidade de água para irrigação, considerando os aspectos de salinidade e sodicidade das águas, proposto pelo United States Department of Agricultural - USDA (RICHARDS, 1954).

Tabela 1- Critérios para classificação da restrição de uso das águas para irrigação segundo United

\begin{tabular}{|c|c|c|}
\hline Classes & Grau de Restrição & Limites \\
\hline \multicolumn{3}{|c|}{ Salinidade - CE $\mu$ S. $\mathrm{cm}^{-1}$} \\
\hline C1 & Baixo & $<250$ \\
\hline $\mathrm{C} 2$ & Médio & $250-750$ \\
\hline C3 & Alto & $750-2250$ \\
\hline C4 & Muito Alto & $>2250$ \\
\hline
\end{tabular}
States Department of Agricultural - USDA (RICHARDS, 1954).

\begin{tabular}{lcc}
\hline & & Sodicidade - RAS \\
S1 & Baixo & RAS $<18,87-4,44 \operatorname{logCE}$ \\
S2 & Médio & $18,87-4,44 \operatorname{logCE}<$ RAS $<31,31-6,66 \operatorname{logCE}$ \\
S3 & Alto & $31,31-6,66 \operatorname{logCE}<$ RAS $<43,75-8,87 \log C E$ \\
S4 & Muito Alto & RAS $>43,75-8,87 \operatorname{logCE}$ \\
\hline
\end{tabular}

Fonte: Adaptado - United States Department of Agricultural (RICHARDS, 1954)

Na Tabela 2 observam-se os padrões de qualidade de água para irrigação, considerando os aspectos de salinidade e sodicidade das águas, proposto pelo
University of California Commitee of Consultants - UCCC e pelos critérios estabelecidos por Ayers e Westcot (1999).

Tabela 2 - Critérios para classificação da restrição de uso das águas para irrigação segundo University of California Commitee of Consultants - UCCC (AYERS; WESTCOT, 1999).

\begin{tabular}{lcccc}
\hline \multirow{2}{*}{ Problemas potenciais } & \multirow{2}{*}{ Unidade } & \multicolumn{3}{c}{ Grau de restrição para uso } \\
\cline { 3 - 5 } & & Nenhum & Moderado & Severo \\
\hline Salinidade & $\mu S . \mathrm{cm}^{-1}$ & $<1$ & $\mathrm{C} 2$ & $\mathrm{C} 3$ \\
$\mathrm{CE}$ & & $\mathrm{S} 1$ & $700-3000$ & $>3000$ \\
\hline Sodicidade - Infiltração & $>700$ & $\mathrm{~S} 2$ & $\mathrm{~S} 3$ \\
$\mathrm{RAS}^{\circ}=0-3 \quad$ e CE $=$ & $>1200$ & $1200-300$ & $<200$ \\
$\mathrm{RAS}^{\circ}=3-6 \quad$ e CE $=$ & $>1900$ & $1900-500$ & $<300$ \\
$\mathrm{RAS}^{\circ}=6-12 \quad$ e CE $=$ & & &
\end{tabular}


$\mathrm{RAS}^{\circ}=12-20$ e $\mathrm{CE}=$

$>2900$

$2900-1300$

$<1300$

$\mathrm{RAS}^{\circ}=20-40$ e CE $=$

$>5000$

$5000-2900$

$<2900$

Fonte: Adaptado - Univerity of California Committee of Consultants (AYERS; WESTCOT, 1999)

Através do programa QualiGraf, que é uma ferramenta para auxiliar na parte gráfica das análises mais usuais de qualidade de água, foi elaborado o diagrama de Piper para a classificação do tipo químico das águas superficiais e subterrâneas de acordo com o conteúdo iônico dominante (MÖBÜS,2003).

Para as análises estatísticas dos dados visando auxiliar na caracterização do efeito da espacialização das águas superficiais e subterrâneas., desenvolveu-se uma análise exploratória pelo emprego da técnica de "Boxplot" com o uso do software do Statistical Package for Social Science for Windows - SPSS 20.0,.

\section{RESULTADOS E DISCUSSÃO}

Analisando as águas superficiais, o açude apresentou valores de CE entre $151 \mu \mathrm{S} . \mathrm{cm}^{-1} \mathrm{e}$ $350 \mu \mathrm{S} . \mathrm{cm}^{-1}$, sendo que $50 \%$ estão no limite de risco baixo $\left(250 \mu \mathrm{S} . \mathrm{cm}^{-1}\right)$ e $50 \%$ com risco médio (750 $\mu \mathrm{S} . \mathrm{cm}^{-1}$ ) (Figura 3 ), segundo a classificação proposta por Richards (1954). O rio perenizado apresentou o mesmo comportamento com valores de CE entre 201 $\mu \mathrm{S} . \mathrm{cm}^{-1}$ a $370 \mu \mathrm{S} . \mathrm{cm}^{-1}$ (Figura 3), tendo baixa variação e também com risco baixo e médio para uso na irrigação. De acordo com Richards (1954) essas águas superficiais podem ser utilizadas na maioria das culturas e em quase todos os tipos de solos, sempre e quando houver uma lixiviação moderada de sais. Em ambos os sistemas hídricos superficiais, açude Trussu e rio perenizado, todos os pontos de coletas avaliados apresentaram CE abaixo do limite $700 \mu \mathrm{S} . \mathrm{cm}^{-1}$, sem nenhuma restrição para fins de irrigação, podendo serem utilizadas em culturas sensíveis a sais (AYERS; WESTCOT, 1999). A presença de águas superficiais apresentando nenhuma restrição para irrigação, quanto à salinidade expressa pela CE das águas, também foram observadas na região semiárida do Ceará nas bacias Metropolitana, Alto Jaguaribe, Curu e Acaraú (ARAÚJO NETO et al., 2014; BARROSO et al., 2011; FROTA JÚNIOR et al., 2007; VASCONCELOS et al., 2009).

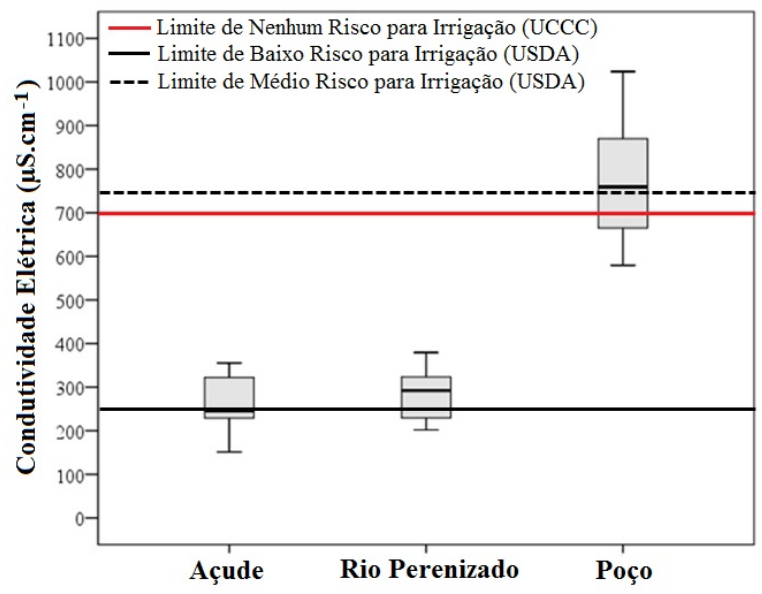

Figura 3. Variabilidade da Condutividade elétrica nos três sistemas hídricos monitorados na bacia do Trussu, Ceará.

Já quando se observa os valores das águas subterrâneas, o sistema hídrico dos poços apresentou valores de CE superiores aos outros dois sistemas de águas superficiais monitorados (Figura 3). Verifica-se pelos intervalos interquartílicos que um percentual maior que 50 $\%$ das amostras estiveram acima do limite de risco moderado para irrigação e uma menor parte com limite nenhum risco, segundo limites proposto por Ayers e Westcot (1999), indicando maior teor e variação espacial das concentrações de sais. Esses resultados ocorrem em decorrência de diversos fatores: climáticos, as condições edáficas e aos métodos de irrigação empregados. Os sais dissolvidos na água de irrigação podem se acumular no perfil do solo, tal acumulação comprometerá a qualidade do solo e, em consequência (através do ciclo da água no sistema), contribuirá, também, para a degradação da qualidade das águas subterrâneas (ANDRADE et al., 2010b). A composição química da água subterrânea é resultado, também, do combinado da composição da água que percola pelo solo e da evolução química, influenciada diretamente pela litologia local. O teor de substâncias 
dissolvidas nas águas subterrâneas aumenta à medida que prossegue no seu movimento no perfil do solo (ANDRADE et al., 2010b; BARROSO et al., 2011).

De acordo com a classificação de Richards (1954) as águas subterrâneas dos poços monitorados apresentaram concentrações de sais classificando-se como de médio risco (Figura 3) (podendo ser usada na irrigação quando houver lixiviação de sais) e alto risco (não pode ser usada em solos com drenagem deficiente). Águas com restrições elevadas para irrigação podem ser utilizadas em solos com alta permeabilidade, sem camadas compactadas e devem ser usadas para a irrigação de plantas com tolerância a sais de moderada a alta com práticas de controle de salinidade (MEIRELES et al., 2010).

Quando se avalia a variabilidade da RAS para os três sistemas hídricos (Figura 4), observa-se que tanto para RAS como para RAS $^{\circ}$, houve menor amplitude representada pela abertura das caixas nos gráficos em análises. Essas menores amplitudes foram observadas tanto para as águas superficiais do açude trussu como para o rio perenizado do Trussu, indicando uma baixa variância espaçotemporal da sodicidade das águas superficiais. Verifica-se que os valores de RAS apresentaram baixo risco de sodicidade, ou seja, baixa concentração de sódio em relação às concentrações de cálcio + magnésio. Richards (1954) descreve que águas com baixa sodicidade podem ser usadas para irrigação na maioria dos solos, com pouca probabilidade de se atingir níveis perigosos de sódio trocável. O mesmo comportamento foi demonstrado na avaliação da $\mathrm{RAS}^{\circ}$, onde as águas apresentaram valores sempre com restrição nenhum risco para irrigação $(<3)$, segundo Ayers e Westcot (1999). Palácio et.al. (2011), estudando a similaridade e fatores determinantes na salinidade das águas superficiais do Ceará, por técnicas multivariadas, também encontrou valores $(<3)$ apresentando baixo risco de causar problemas de infiltração no solo. Lobato et al. (2008), avaliando a qualidade da água de irrigação do Distrito Irrigado Baixo Acaraú, Ceará, observaram que as mesmas não apresentam limitações de uso para irrigação, com valores de RAS apresentando baixo perigo de sodificação dos solos.



Figura 4. Variabilidade da Razão de Adsorção de Sódio (RAS) e Razão de Adsorção de Sódio corrigida $\left(\mathrm{RAS}^{\circ}\right)$ nos três sistemas hídricos monitorados na bacia do Trussu, Ceará.

No entanto, quando se avalia as águas subterrâneas, verifica-se que houve uma maior amplitude e variação espaço-temporal (Figura 3), com valores de RAS apresentando médio a alto risco de sodicidade. Destes resultados apontam para a necessidade de manejos de irrigação como alta lixiviação dos sais e uma boa drenagem de acordo com a classificação para a irrigação de Richards (1954). Andrade Júnior et al. (2006), estudando a qualidade da água subterrânea do semiárido do Piauí, observaram vários poços localizados nos municípios de Itainópolis, Picos, Alagoinha, Campo Grande do Piauí, Alagoinha do Piauí e Monsenhor Hipólito com características químicas associadas à concentração eletrolítica da água subterrânea inferem elevado perigo de sodificação do solo, levando a restrição quanto ao uso na irrigação.

De acordo com o diagrama de Piper, observase o tipo hidroquímico das águas para os três sistemas hídricos: açude Trussu (Figura 5), rio perenizado (Figura 6) e poços no vale do rio Trussu (Figura 7). Os triângulos servem para classificar a água baseada nos cátions e nos ânions dominantes, o qual fornece a distribuição iônica total, isto é, indica a característica química da água e aponta semelhanças entre várias águas (CONCEIÇÃO; BONOTTO, 2002). As águas superficiais do açude e do rio perenizado do Trussu apresentaram predominância quanto aos 
cátions de águas mistas representando $64 \%$ e $80 \%$, respectivamente (Tabela 3). A predominância de águas mistas também foram encontradas por Lobato et al. (2008) nas águas superficiais do baixo Acaraú, Ceará. Em segunda predominância nas águas do açude Trussu um percentual de 34\% das amostras apresentaram classificadas como cálcicas. Destaca-se nas águas superficiais, tanto do açude como do rio perenizado, baixas predominâncias de águas sódicas, representando respectivamente $2 \%$ e $12 \%$ do total de amostras.

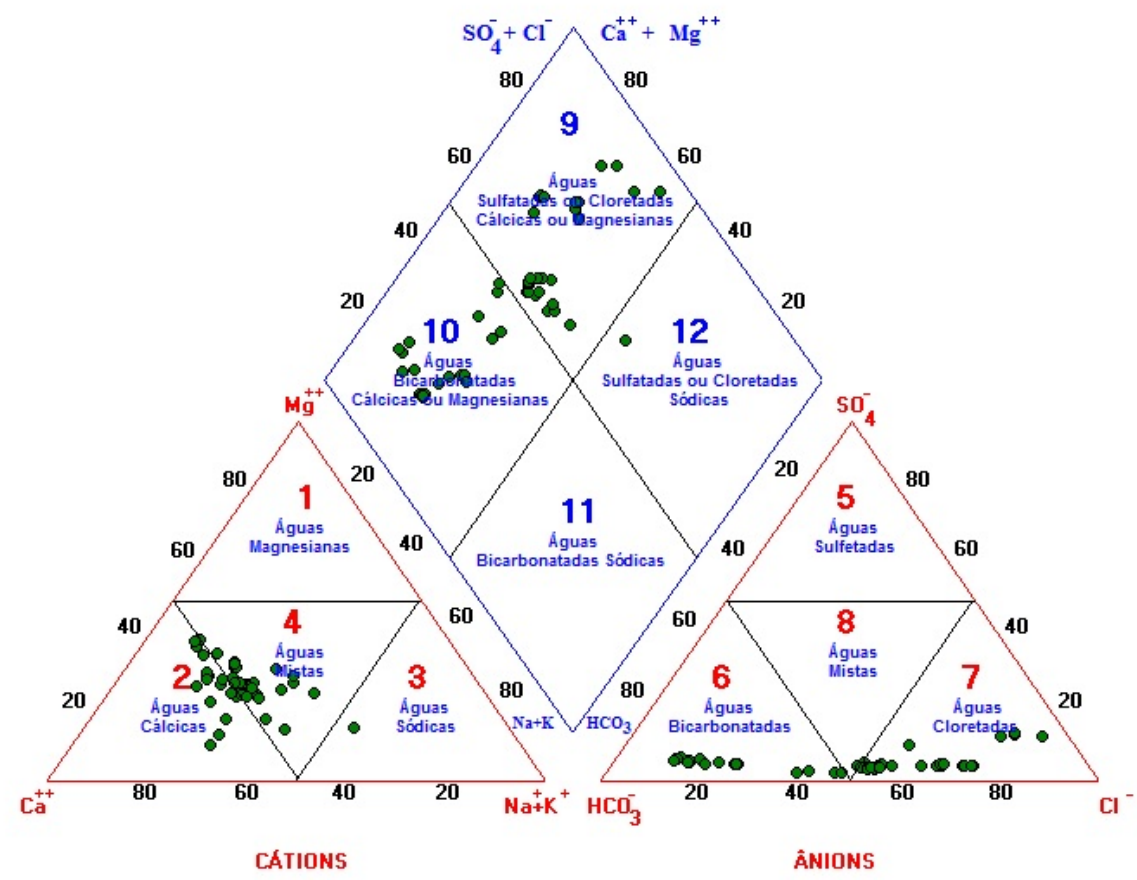

Figura 5. Diagrama de Piper para a classificação das águas do açude Trussu para irrigação.

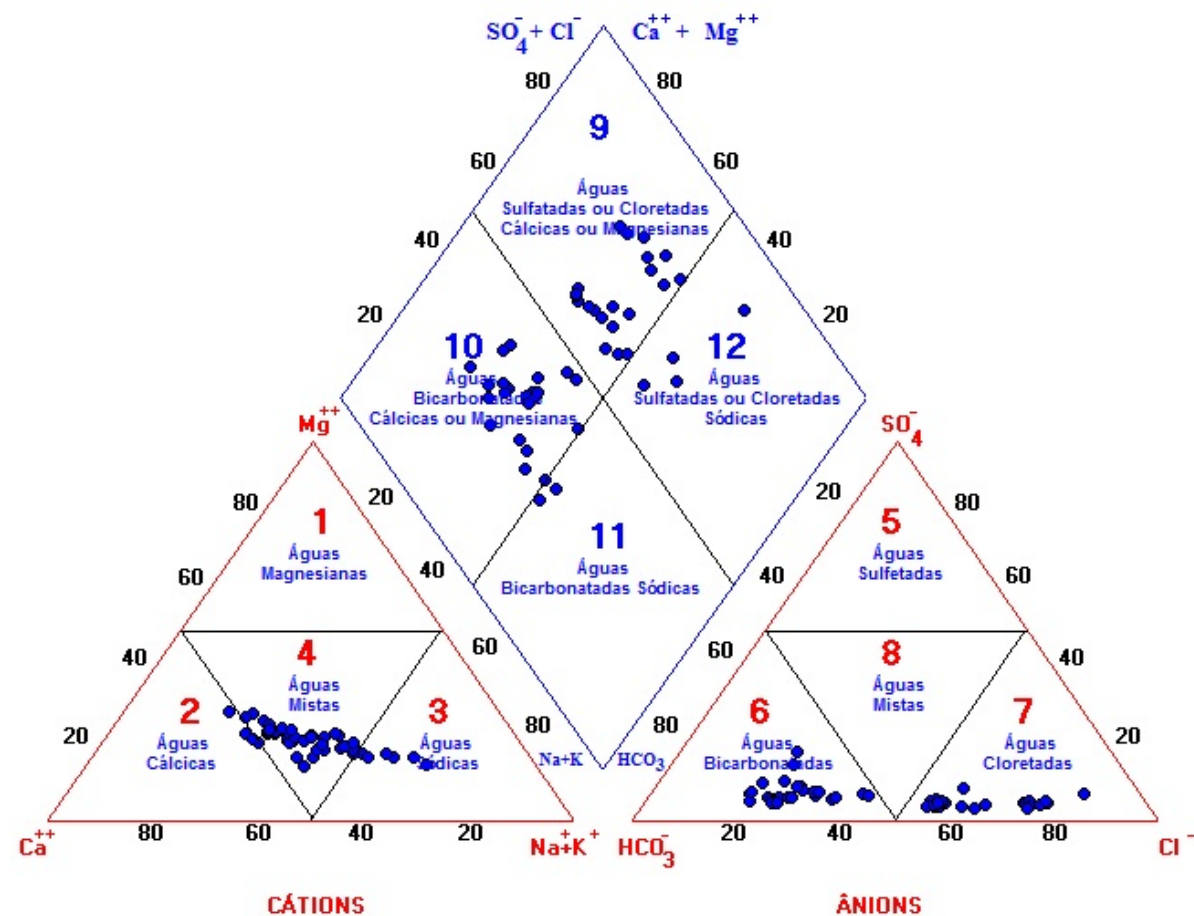

Figura 6. Diagrama de Piper para a classificação das águas do rio perenizado do Trussu para irrigação. 


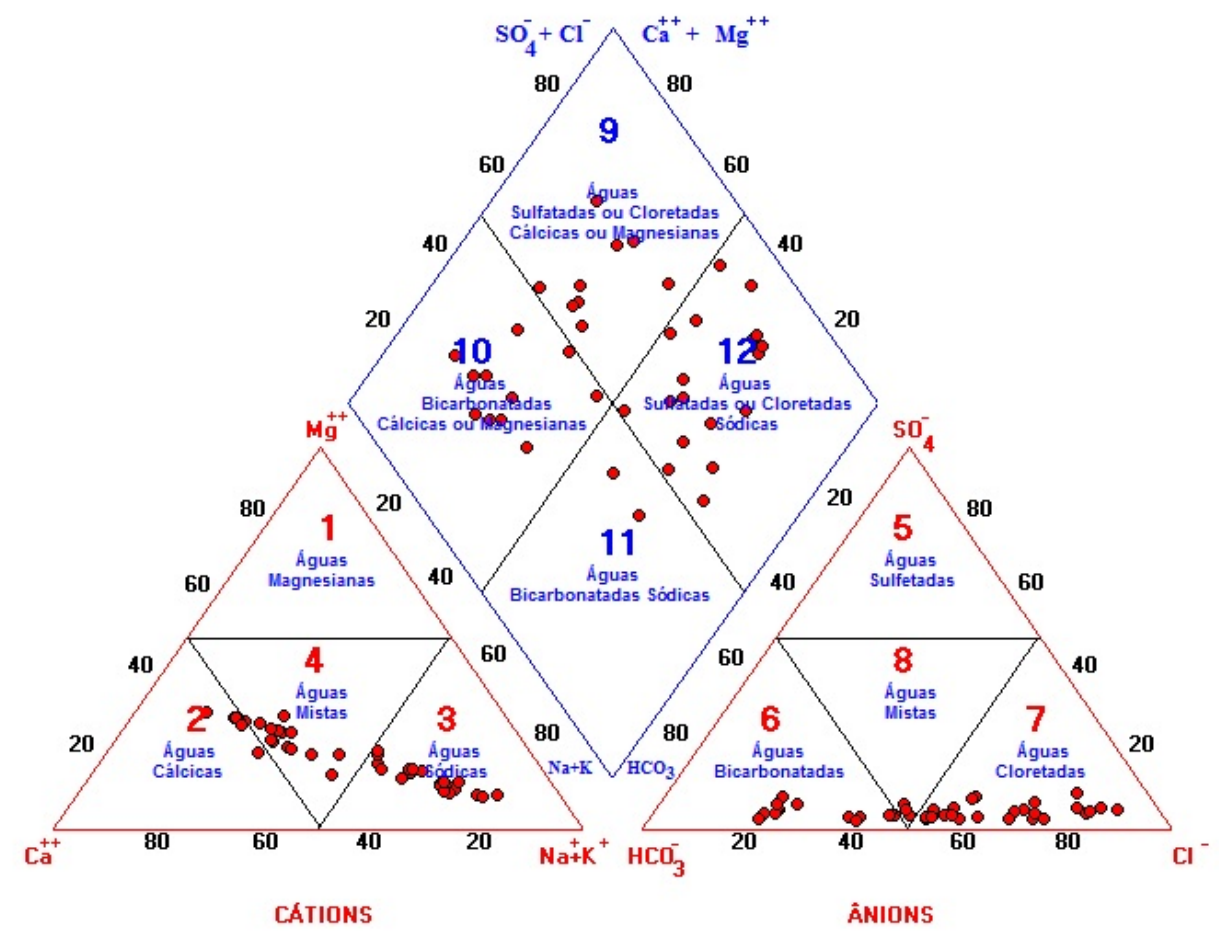

Figura 7. Diagrama de Piper para a classificação das águas dos poços Trussu para irrigação.

Tabela 3 - Percentual da classificação de Piper para as coletas realizadas nos três sistemas hídricos monitorados na bacia do Trussu, Ceará.

\begin{tabular}{lccc}
\hline \multicolumn{1}{c}{ Classificação de Piper } & Açude & Rio Perenizado & Poço \\
\hline Cátions & $\%$ & $\%$ & $\%$ \\
\cline { 1 - 3 } & 0.0 & 0.0 & 0.0 \\
Cálcica & 34.0 & 8.0 & 17.5 \\
Sódica & 2.0 & 12.0 & 50.0 \\
Mista & 64.0 & 80.0 & 32.5 \\
\hline Ânions & $\%$ & $\%$ & $\%$ \\
\hline Sulfetada & 0.0 & 0.0 & 0.0 \\
Bicarbonatada & 40.0 & 50.0 & 32.5 \\
Cloretada & 60.0 & 50.0 & 60.0 \\
Mista & 0.0 & 0.0 & 7.5 \\
\hline Geral & $\%$ & $\%$ & $\%$ \\
\hline Cloretada Cálcica ou Magnesiana & 58.0 & 42.0 & 22.5 \\
Bicarbonatada Cálcica ou Magnesiana & 40.0 & 46.0 & 27.5 \\
Bicarbonatada Sódica & 0.0 & 4.0 & 5.0 \\
Cloretada Sódica & 2.0 & 8.0 & 45.0 \\
\hline
\end{tabular}

Quanto aos ânions nas águas superficiais do açude e rio perenizado, à predominância de águas cloretadas e bicarbonatadas pode estar associada à relação com os períodos chuvosos e estiagem, bem como a resposta do reservatório aos sucessivos anos com precipitação abaixo da média da região. As águas foram classificadas como cloretadas $40 \%$ das águas do açude Trussu e 60\% para o rio perenizado (Tabela 3), correspondendo a parte das amostras dos meses fev/14 a jul/14 e maio/15 que corresponde ao período chuvoso na região. A presença de águas 
cloretadas na estação chuvosa pode estar relacionada aos resíduos de fertilizantes cloretados e cargas de esgotos domésticos provenientes da contribuição do escoamento neste período (ARAÚJO NETO et al., 2010). A predominância de águas bicarbonatadas, em $40 \%$ das amostras no açude e $50 \%$ no rio perenizado, corresponde às coletas realizadas entre $a b r / 13$ a set/13, período em que o reservatório encontrava-se com capacidade de armazenamento entre $40 \%$ a $50 \%$. Resultados de predominância de águas bicarbonatadas foram encontradas por Sardinha et al.(2008) estudando a composição iônica das águas do Ribeirão do Meio, SP, e por Lobato et al. (2008) estudando a água do rio Acaraú, CE.

As águas subterrâneas mostraram um comportamento quanto aos cátions semelhantes ao das águas superficiais, a sua predominância foi de águas sódicas totalizando $50 \%$ das amostras em estudo. As demais foram classificadas como cálcica e mista $(17,5 \%$ e 32,5\%). Barroso et al. (2010) estudando as águas subterrâneas na região do Baixo Jaguaribe - Ceará verificaram que $(87,5 \%)$ das suas amostras se enquadraram na classe de águas sódicas. Quanto aos ânions a sua predominância foi de águas cloretadas e bicarbonatadas com $\quad 60 \%$ e $32,5 \%$ respectivamente.

No geral, as águas subterrâneas foram classificadas como cloretadas sódicas, totalizando $45 \%$ das amostras. Esse comportamento também foi observado por Andrade et al. (2010a) no estado do Ceará, onde suas águas foram classificadas como cloretadas sódica. Os referidos autores ressaltam que esse comportamento pode ser explicado principalmente pelos fatores edáficos e hidrogeológicos. De acordo com Silva Júnior et al. (2000) as águas do cristalino do Nordeste brasileiro classificam-se, na sua maioria, como cloretadas sódicas com alguma variação, de acordo com a litologia do local de origem. Este comportamento também foi verificado para as águas subterrâneas do vale do rio Trussu.

\section{CONCLUSÃO}

As águas superficiais, de acordo com as classificações do USDA e UCCC apresentaram baixo risco de gerar problemas de salinidade, sendo que as águas subterrâneas apresentaram risco de médio a alto em causar problemas de salinidade nos solos com seu uso na irrigação;

As águas superficiais apresentaram baixo ou nenhum risco de causar problemas de sodicidade de acordo ainda com USDA e UCCC. Diferentemente, as águas subterrâneas apresentaram problemas de sodicidade de médio a alto e suas águas só devem ser utilizadas em solos e plantas que tolerem altas quantidades de sais ou sempre que houver lixiviação dos mesmos.

Quanto à predominâncias dos cátions e ânions, a maior parte das amostras de águas superficiais se enquadram na classe cloretadas cálcica e bicarbonatada cálcicas e as águas subterrâneas com quase 45\% das amostras são classificadas como cloretadas sódica.

\section{REFERÊNCIAS}

ANDRADE JÚNIOR, A. S.; SILVA, E. F. F.; BASTOS, E. A.; MELO, F. B.; LEAL, C.M. Uso e qualidade da água subterrânea para irrigação no Semi-Árido piauiense. Revista Brasileira de Engenharia Agrícola e Ambiental, v.10, n.4, p.873-880, 2006.

ANDRADE, E. M.; AQUINO, D. N.; CRISOSTOMO, L. A.; RODRIGUES, J. O.; CHAVES, L. C. G. Similaridade da composição hidroquímica das águas freáticas do perímetro irrigado do Baixo Acaraú, Ceará, Brasil. Revista Agro@mbiente On-line, v.4, n.1, p.11-19, 2010a.

ANDRADE, E. M.; LOPES, F. B.; PALÁCIO, H. A. Q.; AQUINO, D. N.; ALEXANDRE, D. M. B. Land use and groundwater quality: The case of Baixo Acaraú Irrigated Perimeter, Brazil. Revista Ciência Agronômica, v.41, n.2, p.208-215, 2010b.

ANTAS, F. P. S.; MORAIS, E. R. C. Monitoramento da qualidade química da água para fins 193 de irrigação no rio Açú, Rn. 
HOLOS, v.4, p.23-28, 2011.

ARAÚJO NETO, J. R.; MEIRELES, A. C. M.; PALÁCIO, H. A. Q.; ANDRADE, E. M., LIMA, J. S. Caracterização hidroquímica e dinâmica qualitativa da águas superficiais do açude Orós para fins de irrigação. In: Simpósio de Recursos Hídricos do Nordeste, 10., Anais... Fortaleza. X SRHNE. , 2010.

ARAÚJO NETO, J. R.; Sales, M. M.; MEIRELES, A. C. M.; PALÁCIO, H. A. Q.; CHAVES, L.C.C. Modelagem da estrutura iônica das águas superficiais de reservatórios da bacia Metropolitana do Ceará, Brasil usando regressão linear múltipla. Revista Agro@mbiente On-line, v.8, n.1, p.29-38, 2014.

ARRAES, F. D. D.; ANDRADE, E. M.; PALÁCIO, H. A. Q.;SOUSA, C. H. C.; SILVA, J. A.; FROTA JÚNIOR. J. I. Dinâmica da classificação das águas da bacia do Curu. In: Simpósio Brasileiro de Recursos Hídricos, 17., 2007, São Paulo. Anais... Porto Alegre: ABRH. 1 CD.

AYERS, R. S.; WESTCOT, D. W. A qualidade da água na agricultura. 2. ed. Campina Grande, 1999.Tradução Gheyi, H. R.; Medeiros, J. F.; Damasceno, F.A. V.

BARROSO, A. A. F.; GOMES, G. E.; LIMA, A. E. O. PALÁCIO, H. A. Q.; LIMA, C. A. Avaliação da qualidade da água para irrigação na região Centro Sul no Estado do Ceará. Revista Brasileira de Engenharia Agrícola e Ambiental, v.15, n.6, p.588-593, 2011.

BARROSO, A. A. F.; NESS, R. L. L.; GOMES FILHO, R. R.; SILVA, F. L.; CHAVES, M. J. L.; LIMA, C. A. Avaliação Qualitativa das Águas Subterrâneas Para Irrigação na Região do Baixo Jaguaribe - Ceará. Revista Brasileira de Agricultura Irrigada v.4, n.3, p.150-155, 2010.

CONCEIÇÃO, F.T.; BONOTTO, D.M. Relações hidroquímicas aplicadas na avaliação da qualidade da água e diagnóstico ambiental na bacia do Rio Corumbataí (SP). Geochimica Brasiliensis, n.16, n.1, p.1-21, 2002.

FROTA JUNIOR, J. J.; ANDRADE, E. M.; MEIRELES, A. C. M.; BEZERRA, A. M. E.; SOUZA, B. F. S. Influencia antrópica na adição de sais no trecho perenizado da bacia hidrográfica do Curu, Ceara. Revista Ciência Agronômica, v.38, n.02, p.142-148, 2007.

GHEYI, H. R.; Vital Pedro da Silva Paz (Org.) ; Medeiros, Salomão de S. (Org.) ; GALVÃO, Carlos de Oliveira (Org.) . Recursos hídricos em regiões semiáridas: estudos e aplicações. 1. ed. Cruz das Almas: , 2012. v. 1. 258p.

LOBATO, F. A. O.; ANDRADE, E. M.; MEIRELES, A. C. M.; CRISOSTOMO, L. A. Sazonalidade na qualidade da água de irrigação do Distrito Irrigado Baixo Acaraú, Ceará. Revista Ciência Agronômica, v.39, n.01, p.167-172, 2008.

MEIRELES, A.C.M.; ANDRADE, E.M.; CHAVES, L.C.G.; FRISCHKORN, H.; CRISOSTOMO, L.A. A new proposal of the classification of irrigation water. Revista Ciência Agronômica, v.41, n.3, p.349-357, 2010.

MÖBÜS, G. QUALIGRAF. Programa para Análise da Qualidade de água. FUNCEME, 2003. Disponível em: http://www3.funceme.br/qualigraf/ Acesso em: 17. Dez. 2015.

PALÁCIO, H. A. Q.; ARAÚJO NETO, J. R..; MEIRELES, A. C. M.; CHAVES, L. C. G. Similaridade e fatores determinantes na salinidade das águas superficiais do ceará, por técnicas multivariadas. Revista Brasileira de Engenharia Agrícola e Ambiental, v.15, n.4, p.395-402, 2011.

SARDINHA, D. S.; CONCEIÇÃO, F. T.; SOUZA, A. D. G.; SILVEIRA, A.; JULIO, M.; GONÇALVES, J. C. L. I. Avaliação da qualidade da água e autodepuração do Ribeirão 
do Meio, Leme (SP). Engenharia Sanitária e Ambiental. v.13, n.3, p.329-338, 2008.

SUASSUNA, J; AUDRY, P. A Salinidade das águas disponíveis para a pequena irrigação no sertão nordestino: Caracterização, variação sazonal e limitações de uso, Recife: CNPq, 128 p., 1995.
VASCONCELOS, R. C.; LEITE, K. N.; CARVALHO, C. M. de. ; ELOI, W. M.; SILVA, L. M. F. FEITOZA, H, O. Qualidade da água utilizada para irrigação na extensão da microbacia do Baixo Acaraú. Revista Brasileira de Agricultura Irrigada v.3, n.1, p.30-38, 2009. 